\title{
LA UTOPÍA DE LA TRANSDICIPLINA, UNA REFLEXIÓN CRÍTICA DESDE LA NOCIÓN DE DISPOSITIVO DE M. FOUCAULT
}

Dra. Diana Lizbeth Ruiz Rincón ${ }^{1}$

\section{RESUMEN}

Los modos en los que un dispositivo tiende a desplegarse deja de manifiesto dos formas, a manera de linealidades no uniformes o paralelas, aspectos de visibilidad e invisibilidad, esto es: elementos que en la urdimbre de los procesos de formatividad en campos del conocimiento científico que apelan a los principios epistemológicos, teóricos y metodológicos emanados desde el posicionamiento de lo transdisciplinar, pueden nombrarse y otros cuya categorización demanda el ejercicio analítico/investigativo. La noción de dispositivo que se recupera de los planteamientos teóricos de Michael Foucault, permiten trasladar un análisis críticoreflexivo sobre la ciencia o bien sobre el fenómeno científico respecto a la polución de la información y la generación de conocimiento, en relación a la diseminación de las fronteras disciplinares como uno de los pilares que el ejercicio surgido desde la filosofía de la ciencia debe procurar en la época contemporánea.

Así, la metainvestigación de noveles campos de estudio, como el de los Estudios Regionales, cuya apelación epistemológica apunta a una utopía de la transdiciplina, habrá de permitir visibilizar de manera crítica los alcances, riesgos y compromisos que los procesos de formatividad en un campo en construcción

\footnotetext{
${ }^{1}$ Doctora en Estudios Regionales, Facultad de Humanidades C-VI, Universidad Autónoma de Chiapas.
} 
| Cuatrimestral Facultad de Humanidades Campus VI Reserva de Derechos al Uso Exclusivo No.: 04-2018-060814012200-203| ISSN: 2594-1755 Año III | Número 7 | Septiembre- Diciembre 2019

\section{ARTÍCULOS}

a ella siempre será parcial y estará limitado por condiciones fácticas. Sin embargo, la adecuación plena de nuestros juicos a la realidad es una idea regulativa de la razón a la que se aproxima progresivamente, en etapas sucesivas, el conocimiento dela especie. (Villoro, 2009, p. 195)

Todos somos sujetos epistémicos respecto de ciertas razones $\mathrm{y}$, por ende, respecto a ciertos saberes y no respecto a otros. Por lo tanto, todos formamos parte de determinadas comunidades epistémicas [en plural y no singular]. (...) Cada comunidad epistémica delimita, así, un conjunto de razones accesibles, de acuerdo con la información de que se puede disponer, con su nivel de tecnología, con el desarrollo de su saber precio y con el marco conceptual básico que supone. (Villoro, 2009, p. 148)

Podría decirse entonces, que nos encontramos a las orillas de determinadas comunidades epistémicas, que sólo nos ubicamos como sujetos epistémicos al margen de las dinámicas internas de dichas comunidades; pero una vez logrando la pertinencia (o pertenencia), seremos sujetos que habrán de juzgar las razones de determinado saber.

Dicho de otra manera, será mediante la educación que un sujeto epistémico se transforma en un sujeto epistémico pertinente, y al acceder a los conocimientos previos y las razones objetivamente suficientes que fundan determinado conocimiento, estando en condiciones de juzgarlo a su vez. Dicha analogía deja de manifiesto que nos referimos a la formación en la ciencia, la formación en determinado campo, la formación deinvestigadores, en lo regional, de lo regional, en la región, etc. Así nuestro autor señala: 
